\title{
SELECTING THE LOW ALLOY-TEMPERED STEEL FOR MANUFACTURING THE HIGHLY LOADED RESPONSIBLE PARTS
}

The selecting procedure of the optimal material for manufacturing the highly loaded responsible parts for military applications is presented in this paper. The considered part is in exploitation subjected to complex compressive-impact loading and cyclically to high temperatures, as well. The proper selection of material can be done exclusively based on the theoretical and experimental analysis of properties of the steel in question. The theoretical and experimental selecting of adequate steel for manufacturing such parts is done based on requirements arising from their working conditions. Based on the available data for various steels, chemical composition, mechanical and technological properties, available CCT diagram, the optimal steel was selected for the given working conditions. After the selection of the material, experimental investigations on specially prepared material samples were conducted. The real chemical composition of material was established, its most important mechanical properties were determined, the hardness was measured and the microstructure was determined, as well. After the conducted theoretical and experimental investigations, the responsible machine part was manufactured from the selected material by forging. Then, the mechanical and heat processing was executed, after which the part was tested in the real working conditions. Based on investigations of part's behavior in the real working conditions, it was concluded that the selection of the material was adequate.

Keywords: Low-alloyed steel, mechanical properties, microstructure, machine parts.

\section{Introduction}

At the very beginning of the material selection, it is necessary to perform an analysis of all the influential parameters that could lead to that selection to be optimal. The poor material selection can be the cause of various failures and damages, which could bring about both financial losses and injuries [1]. During the selection of material for manufacturing this highly loaded and extremely responsible part, authors of this paper were guided by their own experience, as well as that of other researchers. Though today exist numerous quantitative methods for material selecting, which have been verified as quite reliable, the part made of the selected material must be, at the end, tested in the real exploitation conditions [2]. This is why one can say that the experimental investigations are those that provide for the most reliable results, as well as that this kind of experience can also be achieved during the material selecting for reparation of the damaged machine systems by welding or surfacing/hard facing. In paper [3] authors have shown how a material can be successfully selected and thus the undesired consequences, due to presence of non-metallic inclusions in material, can be avoided. In research reported in [4] it was shown how a reparation of the damaged pulley of a bucket wheel boom hoist system can be successfully executed when the adequate material for hard facing was selected.

Material that is to be selected in this work ought to satisfy all the criteria related to good wear resistance [5 - 9], increased operating temperature [10 - 11], as well as the high pressures, which could be greater than 1000 bar (100 MPa). In material testing, authors were guided by procedures applied by other researchers, as well [8], in order to obtain as relevant results as possible. This paper is, to a certain extent, a report on material investigation and estimate whether it could be successfully used for the given purpose.

\section{The proposed material}

For the machine part, analyzed in this paper, the characteristic loads are the following: impact-compressive, cyclic repetitive and high temperature. Taking into account that the part is a highly

\footnotetext{
* ${ }^{1}$ Vukic Lazic, ${ }^{1}$ Dusan Arsic, ${ }^{1,3}$ Ruzica R. Nikolic, ${ }^{2}$ Miodrag Arsic, ${ }^{3}$ Branislav Hadzima

${ }^{1}$ Faculty of Engineering, University of Kragujevac, Serbia

${ }^{3}$ Institute for testing of materials - IMS, Belgrade, Serbia

${ }^{4}$ Research Center, University of Zilina, Slovakia

E-mail: dusan.arsic@fink.rs
} 
Prescribed chemical composition and mechanical properties of steel $25 \mathrm{CrMo} 4$

Table 1

\begin{tabular}{|c|c|c|c|c|}
\hline \multicolumn{5}{|c|}{ Content of elements, weight $\%$} \\
\hline $\mathrm{C}$ & $\mathrm{Si}$ & $\mathrm{Mn}$ & $\mathrm{Cr}$ & Mo \\
\hline $0.22-0.29$ & $\max 0.40$ & $0.60-0.90$ & 1.05 & 0.25 \\
\hline \multicolumn{5}{|c|}{ Mechanical properties $\emptyset=40-100 \mathrm{~mm}$} \\
\hline$R_{m}, \mathrm{MPa}$ & $R_{p 0,2}, \mathrm{MPa}$ & $A, \%$ & $Z, \%$ & $K C V, J$ \\
\hline 800-950 & $\min .600$ & $\min .15$ & $\min .55$ & $\min .50$ \\
\hline
\end{tabular}

responsible one, the material selection was immediately reduced to alloyed steels. Considering the purpose and the function of the part, based on experience and recommendations from other authors, the selection was narrowed down to low-alloy tempered steel $25 \mathrm{CrMo} 4$ [12]. The prescribed chemical composition and mechanical properties of this material, as per manufacturer's declaration, are shown in Table 1.

Based on these chemical and mechanical properties, as well as on the performed analysis of the fatigue strength and toughness [5-7] and wear resistance [8-9], authors have assumed that this material can fulfill the requirements set for this construction.

\section{Experimental testing}

After the material was selected, the tests on adequate samples were performed. The following properties were tested: chemical composition, mechanical properties, hardness and microstructure. The first two categories were certified by the manufacturer, but they were tested anyway, for the authors had to be certain that declared properties were correct, since any deviation could lead to part's improper functioning or damages and injuries of the user. After all the properties were tested and verified, the tube was produced of the selected material and tested in the real operation conditions.

\subsection{Chemical composition}

The first test was checking of the material's chemical composition. It was done by the optical emission spectrometry, according to the corresponding standard [13]. Obtained results are shown in Table 2. These results have exhibited certain deviations from those specified by the manufacturer, primarily in the content of chromium and molybdenum. This is, however, explained by the aimed military application of the part, where certain other (internal and specific) standards are applicable. The laboratory tests results have established that the considered steel, according to mechanical properties, corresponds the most to steel $25 \mathrm{CrMo} 4$.

The increased chromium content could be explained by the fact that with $\mathrm{Cr}$ increase the steel's hardenability and fire resistance also increase. In addition, in some steels, with carbon content that is higher than needed for creation of perlite, special chromium carbides $\left(\mathrm{Cr}_{23} \mathrm{C}_{6}, \mathrm{Cr}_{7} \mathrm{C}_{3}\right.$ and $\left.\mathrm{Cr}_{3} \mathrm{C}_{2}\right)$ are created, which, if stable, contribute to increased wear resistance. On the other hand, molybdenum in structural steels, with contents $0.20-0.60 \%$, causes grain size decreasing what contributes to increase of toughness and hardenability and decreases affinity of steels to overheating, since $\mathrm{V}$ with carbon forms the carbide (VC), which prevents increase of the grain size.

\subsection{Tensile and impact testing}

After the chemical composition checking, the tensile test on selected material samples was performed. The test was performed in the accredited laboratory on the universal testing machine WPM ZD 40, on the standard cylindrical sample (Fig. 1), according to the adequate standard [14]. In addition, samples for determination of the impact toughness at the room temperature were prepared. The test was done on the Charpy pendulum, according to standard SRPS EN ISO 148-1:2012 [15]. Results of both tests are shown in Table 3.

Analyzed chemical composition of steel $25 \mathrm{CrMo} 4$

Table 2

\begin{tabular}{ccccccccccccc}
\hline \multicolumn{11}{c}{ Content of elements, weight \% } \\
\hline $\mathrm{C}$ & $\mathrm{Si}$ & $\mathrm{Mn}$ & $\mathrm{Cr}$ & $\mathrm{Mo}$ & $\mathrm{Ni}$ & $\mathrm{Cu}$ & $\mathrm{Al}$ & $\mathrm{V}$ & $\mathrm{Ti}$ & $\mathrm{P}$ & $\mathrm{S}$ \\
0.273 & 0.387 & 0.526 & 3.387 & 0.578 & 0.108 & 0.184 & 0.006 & 0.011 & 0.002 & 0.020 & 0.017 \\
\hline
\end{tabular}




\begin{tabular}{|c|c|c|c|c|c|c|}
\hline Material & $\begin{array}{c}\text { Yield strength } \\
R_{p 0.2}, \mathrm{MPa}\end{array}$ & $\begin{array}{c}\text { Tensile strength } \\
\boldsymbol{R}_{m}, \mathrm{MPa}\end{array}$ & $\begin{array}{c}\text { Elongation } \\
\qquad A, \%\end{array}$ & $\begin{array}{c}\text { Contraction Area } \\
\text { reduction } \\
\%\end{array}$ & Impact energy, $J$ & $\begin{array}{c}\text { Hardness } \\
\text { HV } 10\end{array}$ \\
\hline \multirow{2}{*}{$25 \mathrm{CrMo} 4$} & 784 & 925 & 40 & 68 & 143 & 275 \\
\hline & 775 & 923 & 40 & 68 & 142 & 273 \\
\hline
\end{tabular}
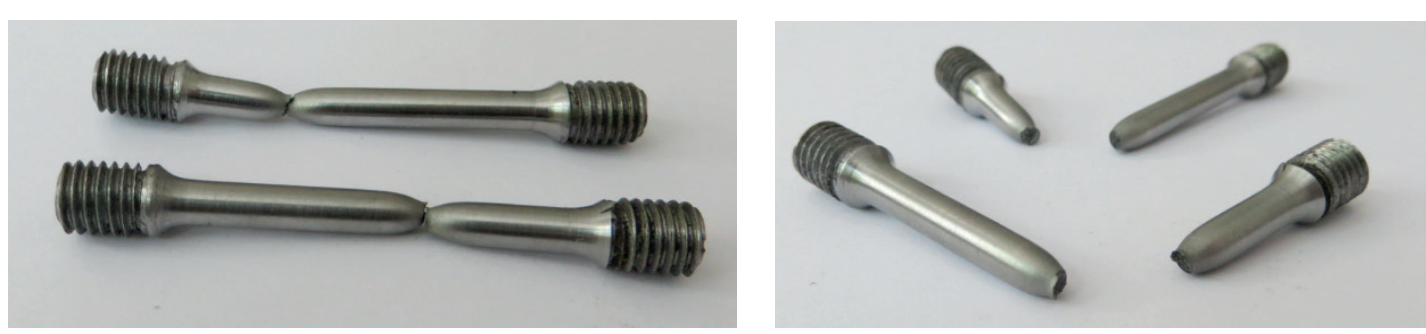

Tensile testing
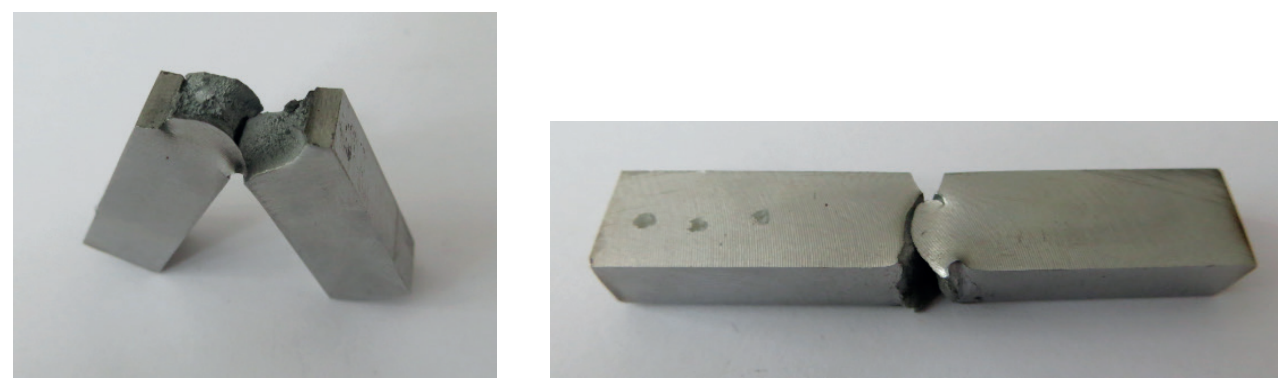

Impact toughness testing

Fig. 1 Broken specimens after testing

Analysis of obtained results confirmed that the data guaranteed by the steel manufacturer were correct and that the material can be used for the planned part manufacturing. In situations when the quick verification of the material properties is needed, one can also use the numerical simulations, which turned out to be quite reliable for checking the materials strength [11].

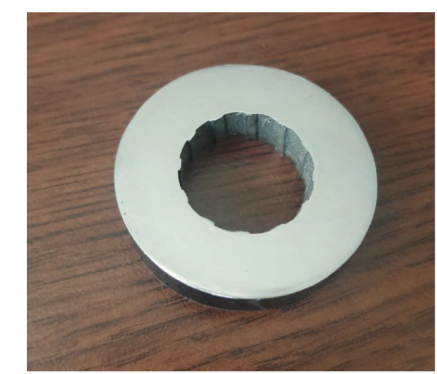

Hardness measurement sample HV 10

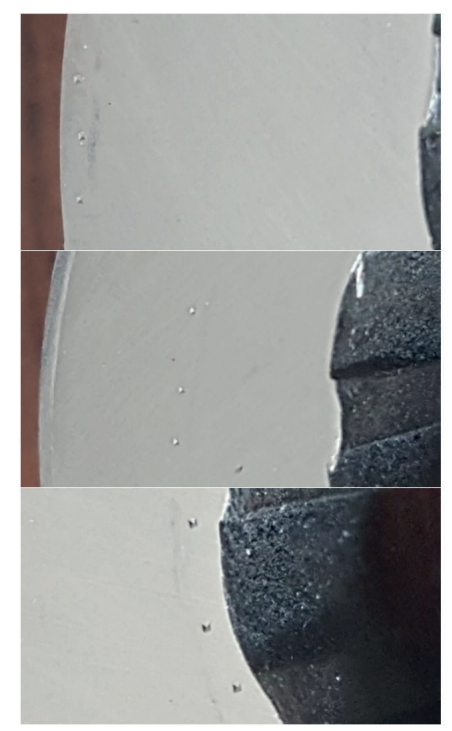

At the outside edge

In the middle of the sample

At the inside edge

Fig. 2 Hardness measurements - sample and places 


\subsection{Hardness measurement and microstructure examination}

The material hardness measurement and testing of microstructure were done on cylindrical ring samples, shown in Figs. 2 and 3. Tests were done at the inside edge of the tube, in the middle and at outside edge of the tube. The samples' hardness was within range 273 to $275 \mathrm{HV}$ (Table 3), while the obtained microstructure appearances are shown in Fig. 3. Considering that the hardness is less than $350 \mathrm{HV}$, one can say that creation of martensite was avoided.

\subsection{Estimate of microstructure based on the CCT diagram}

Obtained microstructure can be also estimated based on the corresponding CCT diagram (Fig. 4). The red-off microstructure - bainite and tempered martensite - corresponds to quenching in water and high tempering, what constitutes the heat treatment prescribed by the steel manufacturer, as well. It is extremely important that there is no pure martensite in the final structure, since it could act as the stress concentrator due to the dynamic loading during the exploitation.

The considered tube was obtained by the following procedures and with the following regimes:
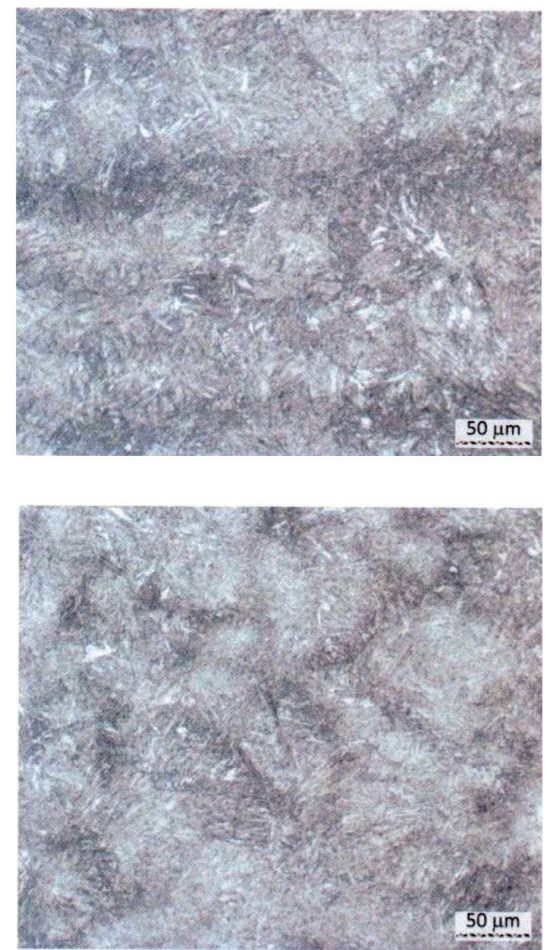

Fig. 3 Microstructure of steel 25CrMo4: tempering microstructure - bainite + tempered martensite

- normalization - at $870{ }^{\circ} \mathrm{C}$;
- forging - at the forging bat from the steel piece heated up to $1100{ }^{\circ} \mathrm{C}$;

- quenching - at $860^{\circ} \mathrm{C}$ and cooling in oil;

- tempering - at $600{ }^{\circ} \mathrm{C}$ and cooling in the furnace.

It is possible to adopt the procedure of continuous bainite or isothermal bainite quenching from the temperature of 860 ${ }^{\circ} \mathrm{C}$, for manufacturing of the considered part, in order to avoid appearance of martensite (Fig. 3). From the CCT diagram (Fig. 4), one can see that the incubation period, since the beginning of the martensite dissolution is approximately $15 \mathrm{~s}$, what must be taken into account during the heat treatment procedure.

\section{Conclusion}

The procedure for selecting and testing of the material for manufacturing the responsible structural part is presented in this paper. The selection was performed primarily based on authors' own experiences, as well as on recommendations from other researchers. Since the part in question is a constituent of a very responsible structure, all the properties of the material were tested. It was confirmed that the material is adequate for the assumed application. It has fulfilled all the exploitation requirements of the structure and the tests on the real, manufactured part were also
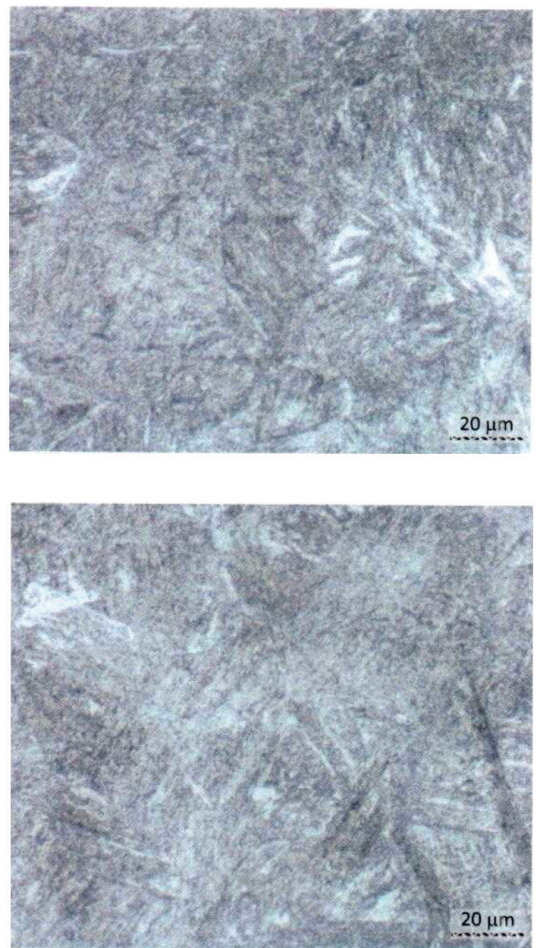
performed. The tube, made of the selected steel by forging, has passed all the tests and trials.

Authors consider that the procedure, presented in this paper, must be obeyed in selection of material for manufacturing the responsible structures and their parts, besides the other theoretical and analytical methods that could be of help.

\section{Acknowledgement}

This research was partially financially supported by the European regional development fund and Slovak state budget by the project "Research Centre of the University of Zilina" - ITMS 26220220183 and by the Ministry of Education, Science and Technological Development of Republic of Serbia through grants: ON174004 and TR35024.

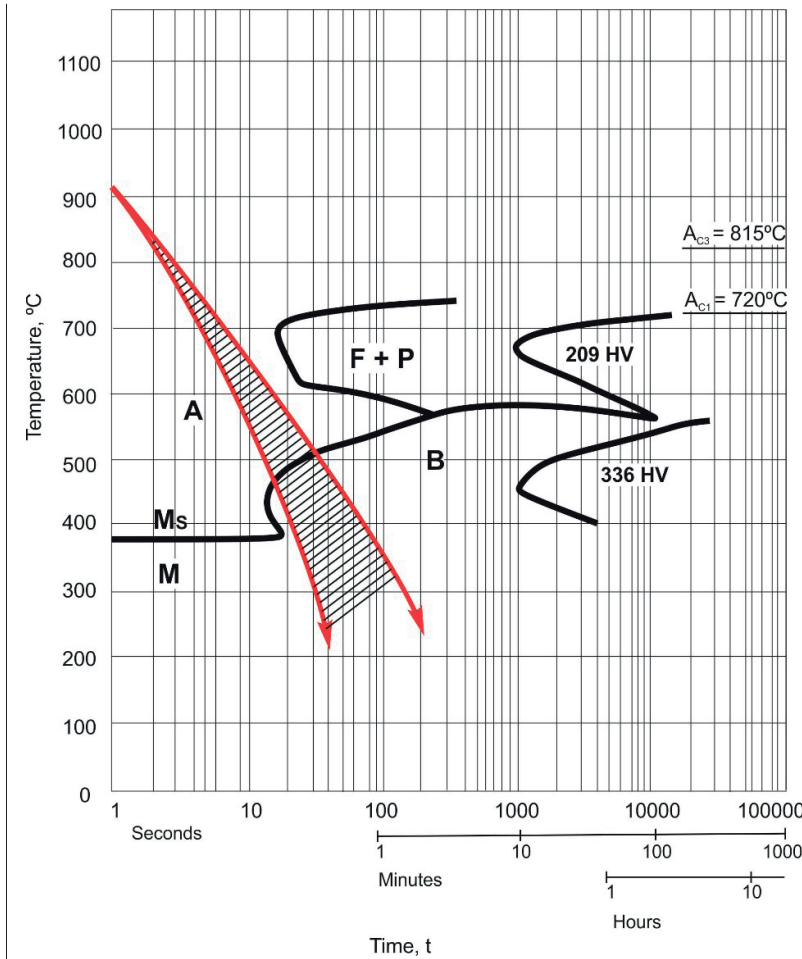

Fig. 4 The CCT diagram for 25CrMo4 steel with shown optimal regime of the continuous bainite quenching

Note: This research was partially reported at the $22^{\text {nd }}$ International Seminar of PhD Students "SEMDOK 2017" - reference [16].

\section{References}

[1] LAZAREVIC, Z., ARANDJELOVIC, I., KIRIN, S.: An Analysis of Random Mechanical Failures of Bucket Wheel Excavator. Structural Integrity and Life, 15(3), 2015, 143-146.

[2] GOLUBIC, S., CIKIC, A., HRSAK B.: Applying Quantitative Methods in the Selection of Materials. Tehnicki glasnik-Technical Journal, 6(1), 1-6, 2012.

[3] ARSiC, D., LAZIC, V., ALEKSANDroVIC, S., NIKOLIC, R., MARINKOVIC, P., DJORDJEVIC, M., RATKOVIC, N.: Theoretical-Experimental Fracture Analysis of a Responsible Machine Part. Structural Integrity and Life, 14(2), 141-146, 2014.

[4] BOSNJAK, S., ARSIC, M., SAVICEVIC, S., MILOJEVIC, G., ARSIC, D.: Fracture Analysis of the Pulley of a Bucket Wheel Boom Hoist System. Eksploatacja i Niezawodnosc-Maintenance and Reliability, 18(2), 155-163, 2016.

[5] LUKE, M., VARFOLOMEEV, I., LUTKEPOHL, K., ESDERTS, A.: Fatigue Crack Growth in Railway Axles: Assessment Concept and Validation Tests. Engineering Fracture Mechanics, 78(5), 714-730, 2011.

[6] VARFOLOMEEV, I., LUKE, M., MOROZ, S.: Experimental and Numerical Investigations of Fatigue Crack Growth in Various Specimen Geometries. Procedia Engineering, 2(1), 1829-1837, 2010.

[7] CARBONI, M., REGAZZI, D.: Effect of the Experimental Technique onto R Dependence of $\Delta \mathrm{K}_{\mathrm{th}}$. Procedia Engineering, 10, 29372942, 2011.

[8] KHANAFI-Benghalem, N., FElder, E., LOUCIF, K., MONTMITONNET, P.: Plastic Deformation of 25CrMo4 Steel during Wear: Effect of the Temperature, the Normal Force, the Sliding Velocity and the Structural State. Wear, 268(1-2), 23-40, 2010.

[9] ARSiC, D., LAZIC, V., MiTroviC, S., DZUNIC, D., ALEKSANDrOVIC, S., DJORDJEVIC, M., NEDELJKOVIC, B.: Tribological Behavior of Four Types of Filler Metals for Hard Facing under Dry Conditions. Industrial Lubrication and Tribology, 68(6), 729-736, 2016. 


\section{COMMNICOIIIONS}

[10] JONSTA, P., VLCKOVA, I., JONSTA, Z., HEIDE, R.: Materials Analysis of Degraded Steam Turbine Rotor. Communications Scientific Letters of the University of Zilina, 18(3), 78-826, 2016.

[11] ARSIC, D., DJORDJEVIC, M., ZIVKOVIC, J., SEDMAK, A., ALEKSANDROVIC, S., LAZIC, V., RAKIC, D.: Experimentalnumerical Study of Tensile Strength of the High-Strength Steel S690QL at Elevated Temperatures. Strength of Materials, 48(5), 687-695, 2016.

[12] EN 10027-1: 2015, Designation systems for steels - Part 1: Steel names.

[13] SRPS C.A1.011: 2004, Methods of chemical analyses - Optical emission spectrometric method with spark excitation for quantitative chemical analyses of pig iron, cast iron, low alloyed steels, high alloyed steels, aluminum alloys and copper alloys (Serbian standard).

[14] EN ISO 6892-1: 2016, Metallic materials - Tensile testing - Part 1: Method of test at room temperature.

[15] SRPS EN ISO 148-1: 2012, Metallic materials - Charpy pendulum impact test - Part 1: Test method (ISO 148-1: 2009).

[16] LAZIC, V., ARSIC, D., NIKOLIC, R., ARSIC, M., HADZIMA, B.: Procedure for Selecting the Low Alloy-Tempered Steel for Manufacturing the Responsible Highly Loaded Parts. Proc. of 22 nd Intern. Seminar of PhD Students (SEMDOK 2017), Slovakia, 72-76, 2017. 